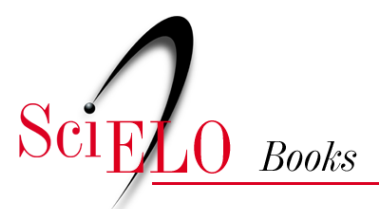

\title{
IV. Revolução do Porto e a volta da Família Real para Portugal
}

\author{
Juliana Gesuelli Meirelles
}

\section{SciELO Books / SciELO Livros / SciELO Libros}

MEIRELLES, J.G. Revolução do Porto e a volta da Família Real para Portugal. In: A família real no Brasil: política e cotidiano (1808-1821) [online]. São Bernardo do Campo: Editora UFABC, 2015, pp. 55-77. ISBN: 978-85-68576-96-0. https://doi.org/10.7476/9788568576960.0005.

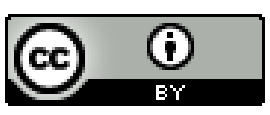

All the contents of this work, except where otherwise noted, is licensed under a Creative Commons Attribution 4.0 International license.

Todo o conteúdo deste trabalho, exceto quando houver ressalva, é publicado sob a licença Creative Commons Atribição 4.0.

Todo el contenido de esta obra, excepto donde se indique lo contrario, está bajo licencia de la licencia $\underline{\text { Creative Commons }}$ Reconocimento 4.0. 
Revolução do Porto e a volta da Família Real para PORTUGAL

Ao final de 1820, era traduzido na Bahia um folheto anônimo em francês cuja autoria foi atribuída a Cailhé de Geine, informante da intendência da polícia baiana, Intitulado Le Rói et la Famille Royale de Bragance DoiventIls, dans lês Circonstances Presentes, Saourner à Portugal, ou Bien Resterau Brésil? O tema do folheto colocava em cena uma polêmica que extrapolava o universo particular das discussões dos ministros de D. João VI desde 1814. O Rei e a família real deveriam ficar no Brasil ou voltar para Portugal?

$\mathrm{O}$ folheto teve grande impacto na Corte, onde gerou importantes discussões, uma vez que defendia a permanência definitiva da Corte no Brasil, a construção de um Império Brasileiro e o abandono de Portugal, em uma clara reação às consequências advindas da Revolução do Porto. Entre as reivindicações dos revolucionários, existia uma proposta que defendia a preservação do Antigo Regime no Brasil ou, em outras palavras, propugnava a manutenção do status de Colônia deste lado do Atlântico.

A reação a essas ideias foi de tal envergadura que as autoridades reais apreenderam os exemplares em circulação. Porém, por mais que o Brasil ainda vivesse sob um aparato censor, que estruturava um dos alicerces do poder real, tal fato já apontava para uma nova realidade: dava-se início à discussão pública de temas políticos verdadeiramente relevantes para o destino da Nação, em que a pluralidade de opiniões se tornava a tônica principal do debate. "Ao contrário do que pretendia o autor, o escrito ampliou o desejo dos luso-brasileiros de agir em uníssono com os constitucionalistas de além-mar", relata a historiadora Lúcia das Neves (2008: 97).

Surgiam as mais diversas formas de julgamento sobre o tema, sobretudo diante de uma proposta tão radical. A ideia de separação entre Brasil e Portugal estava longe de ser um consenso entre a elite luso-brasileira. O conflito político, no entanto, chegava ao seu limite: em agosto de 1820 eclodia na cidade do Porto uma revolução liberal que defendia a bandeira de uma monarquia constitucional. As notícias desse fato político, no entanto, só seriam oficialmente noticiadas no Brasil em novembro do mesmo ano. 
Em 9 de novembro de 1820, a Impressão Régia publicava uma edição extraordinária da Gazeta do Rio de Janeiro. Naquela quinta-feira, a sociedade carioca soube oficialmente sobre a Revolução do Porto - um movimento político liberal - que desde 24 de agosto mantinha a sociedade portuguesa sob constante tensão e conflitos de interesses. No Porto, os revolucionários defendiam uma bandeira patriótica: proclamar a liberdade e a independência nacional, através da necessária Regeneração que, por essa ótica, seria responsável pelo término dos males pretéritos. Porém, a regeneração não foi interpretada pelas elites ilustradas e revolucionárias portuguesas como uma ruptura radical com o passado monárquico, mas como um resgate do "constitucionalismo da monarquia lusitana que se opunha à ideia de um Estado absolutista superdimensionado em suas funções e visto como responsáveis pelos males que assolavam o país" (Silva, 2000: 285). Agora era a existência de uma Constituição, uma lei fundamental, que passaria a assegurar ao povo os laços tradicionais existentes entre eles e o Rei soberano.

As notícias da Revolução chegaram ao Rio cerca de quarenta dias depois e se propagaram como rastilho de pólvora pelas ruas da cidade. A questão, porém, é que esse fato histórico de tamanha relevância para a sustentação do Império luso-brasileiro não parecia ser uma novidade para a elite econômica e política da Corte. Segundo atestava uma folha inglesa traduzida e publicada no Correio do Porto, no dia 20 de outubro, os brasileiros já estavam informados sobre o andamento de um projeto revolucionário em Portugal. "O Brasil está muito inquieto, não sendo improvável que a Revolução de Portugal se estenda além do Atlântico. Cartas da Bahia, Pernambuco, e outras terras do norte do Brasil, escritas por pessoas mui respeitáveis exprimem receios de próximos rompimentos; e até dão a entender que o Projeto de uma Revolução em Portugal era conhecida no Brasil já em Junho passado", informava o periódico.

Como era de se esperar de um súdito fiel de D. João, o então redator da Gazeta, Manuel Ferreira de Araújo Guimarães, anunciava as notícias de modo a enaltecer a monarquia e execrar a figura dos revoltosos. Dizia ele:

O espírito de inquietação e o desatinado desvario, que tem atacado o meio dia da Europa, desgraçadamente soprou sobre uma das mais belas cidades de Portugal, e corrompendo ânimos ambiciosos, e indiscretamente amigos da novidade, causou tumultos efêmeros, que a prudência do Governo se apressou a atalhar e a extinguir. Para darmos aos nossos Leitores uma ideia deste abominável acontecimento, basta copiarmos a seguinte PROCLAMAÇÃO. 
Publicado na seção Rio de Janeiro, o comentário de Guimarães antecedia a inserção de documentos oficiais sobre os acontecimentos ocorridos na cidade do Porto, entre os idos de agosto e setembro. Todas as notícias divulgadas nesse número extraordinário eram extraídas da Gazeta de Lisboa e, curiosamente, limitavam-se ao que fora publicado no periódico lusitano até, precisamente, o dia 2 de setembro de 1820 . Acontece que, desde o dia 5 de setembro, os governadores do Reino enviavam ao Rio as primeiras cartas de ofícios de portugueses e os seus próprios documentos, informando o Rei acerca das providências tomadas pela Regência de Lisboa que, para apaziguar a situação, decidira convocar as Cortes.

Realmente, até o início de setembro, os governadores do Reino lutaram contra a evolução do movimento com as armas que tinham nas mãos: a diplomacia, a força das palavras no universo público e a organização de um corpo militar, responsável por combater os revolucionários do Porto. Em 30 de agosto, o redator da Gazeta de Lisboa considerava o levante um "horrendo crime de rebelião contra o poder, a autoridade legítima do nosso Augusto Soberano, EL-REI Nosso Senhor", cujas atitudes eram frutos de "alguns poucos indivíduos mal intencionados [que] alucinando os chefes dos corpos das tropas daquela cidade; poderão desgraçadamente influí-los" e, assim, romper o juramento de fidelidade ao monarca, já que se atreviam "a constituir por sua própria autoridade naquela cidade um governo a que dão o título de Governo Supremo do Reino", cuja bandeira defendia a monarquia constitucional. 


\section{Num. 205.

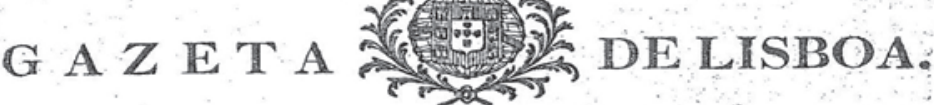

COM PRIVILEGIO DE SUA MAGESTADE.

QUARTA FEIRA 30. DE AGOSTO.

LISBOA 29 de Agosto.

P R O C L A M A C . I O.

7 Dortuguezes! O horrendo crime de rebellião contra o poder, $\mathbf{e}$ Au1 thoridade legitima do nosso Augusto Soberano, ElRei Nosso Senhor, acaba de ser commettido na Cidade do Porto.

Alguns poucos Individuos mal-intencionados, allucinando: os Chefes dos Corpos da Tropa daquella Cidade, pudérăo desgraçadainente influillos paraque, cobrindo-se de opprobrio, quebrassem no dia 24 do corrente o juramento de fidelidade ao seu Rei, és suas Bandeiras, e se atrevessem a constituir, por sua propria Authoridade, naquella Cidade hum Governo a que dăo o titulo de Governo Supremo do Reino. Bem conhecião os perversos, que maquinárão esta conspiração, que só poderião conseguir extraviar coraçőes Portuguezes occultando-lhes, debaixo de apparencias de hum juramento illusorio de amor e fideli2 dade ao sen Soberano, o primeiro, e tremendo passo que thes fizerão dar para o abismo das revoluçôes, cujas consequencias podem ser a subversão da Monarquia; e a sujeição de buma Nação sempre zelosa da sua independencia á ignominia de hum jugo estrangeiro.

Não vos illndais pois, fieis e valorosos Poriuguezes, com semelbantes apparencias : be evidente a contradição com que os revoltosos', protestando obediencia a ElRei Nosso Senhor, se subtrahem:á Authoridade do Governo legitimamente estabelecido por Sua Magestade-, propondo-se, como declarão os intrusos, que a si mesmos se canstituírão debaixo do titulo de Governo Supremo do Reino, a convocar Côrtes, que sempre serão illegaes, quando não forem chamadas pelo. Soberaвo; e a annuciar mudinças, e alterações, que, quando muito; devião limitar-se a pedir, por isso gue só podem emanar legitima', é permanentemente do Real consentimento.

Gazeta de Lisboa, 30/08/1820, $N^{\circ}$ 205. Nessa edição da gazeta oficial, a sociedade lisbonense tomava conhecimento dos fatos ocorridos na cidade do Porto, seis dias antes.

Toda essa problemática vivenciada pelos acontecimentos da Revolução do Porto era resultado de uma conjuntura histórica que permeava a vida política luso-brasileira desde 1815, quando o Brasil fora elevado a Reino Unido de Portugal e Algarves. A conjuntura política era deveras delicada, quase insustentável. Assim, em 15 de setembro, os mesmos governadores que até então defendiam "acirradamente" a manutenção da ordem monárquica absolutista da Dinastia de Bragança sob a chefia de D. João VI formaram uma junta governativa - um governo interino -, acataram as exigências dos "rebelados", ao convocarem as antigas Cortes e assumiram uma nova postura política diante dos fatos e, consequentemente, do próprio Rei. A ausência do monarca acentuava a urgência de medidas que contivessem a situação, corroborando para que os líderes políticos se sentissem aptos e 
livres para dirigirem os destinos do Reino. Nessa data, mudava-se, inclusive, o discurso da Gazeta de Lisboa, que passava a defender o desejo de "toda a nação". "Chegou o momento de sufocar, pela unanimidade de votos da Nação, o gérmen de civis discórdias; já são livres de acanhados terrores as vozes dos Portugueses; conseguiu-se enfim uma justa e moderada liberdade neste dia, duas vezes memorável", refletia o jornalista.

Havia aqueles que criticavam as qualificações dos autores da Revolução do Porto, que eram considerados abomináveis e escandalosos, jamais rebeldes e sediciosos. Por outro lado, também tinham os que já se denominavam brasileiros, apoiavam a separação e defendiam a independência como forma de corrigir os vícios do governo do Brasil, pois era um engano esperar qualquer melhoria advinda do trono. A força do folheto anônimo de fins de 1820 foi tão ampla que a própria Gazeta do Rio Janeiro, em 31 de julho de 1821, anunciava a sua venda "devidamente" analisada. "Na loja da Gazeta se acha vertido em Português e analisado o folheto francês que há tempos se espalhou no Rio de Janeiro, que tinha por título O Rei e a Família real devem nas circunstancias presentes voltar para Portugal ou ficar no Brasil, por 960 réis", informava o anúncio. Contudo, quando a direção da Gazeta decidiu dar publicidade ao impresso, D. João VI e toda a corte já havia retornado para Portugal, assim como as discussões pela definição dos padrões de uma monarquia constitucional já ganhavam acirrados debates nas Cortes de Lisboa.

Em 2 de janeiro de 1821, Cailhé de Geine enviava uma carta a Paulo Fernandes Viana, intendente da polícia no Rio. Neste escrito, relatava o novo caminhar da população baiana depois do conhecimento da Revolução do Porto: as fermentações dos ânimos apareciam de forma mais explícita no universo público. Ninguém mais parecia se preocupar em esconder suas opiniões, revelando-as através da produção de papéis e canções patrióticas que passavam a circular livremente, sendo lidos ou cantados em voz alta pelas ruas (Cartas de C. de Geine ao Intendente da Polícia. BNRJ. Mss. II-33, 22,54. 2 de janeiro 1821).

Essa nova conformação política e suas consequências no cotidiano da sociedade luso-brasileira, mas principalmente da sociedade carioca, aparecem com maior nitidez a partir do raiar do ano de 1821. O final do ano de 1820, entretanto, já sinalizava algumas transformações. Em 19 de dezembro, a sociedade portuguesa era informada pela Gazeta de Lisboa sobre as decisões reais de D. João VI deste lado do Atlântico. O monarca autorizava as Cortes convocadas pelos precedentes Governadores do Reino, reclamando, no entanto, o fato de a convocação ter ocorrido sem o concurso da sua Real Pessoa, o que considerava, particularmente, injusto. A mesma edição também anunciava que logo em breve - assim que concluídas as mesmas Cortes, e sendo remetidas as propostas delas para serem legalizadas com a régia 
sanção - os portugueses teriam no meio de si a real figura de D. João ou a de algum de seus augustos filhos.

Já por essa época, muitas das exigências vigentes na Revolução do Porto apareciam de forma mais nítida nas Cortes, como foi o caso do debate sobre as leis que pautariam a liberdade de imprensa e o fim definitivo da censura régia. Entre os temas de grande relevância para a Constituição, a regulamentação da liberdade de imprensa compôs uma das mais acaloradas discussões entre os deputados. A questão foi de tamanha urgência que, em 5 de fevereiro de 1821, Soares Franco - ex-redator da Gazeta de Lisboa no período das Guerras Napoleônicas - apresentava um projeto de decreto sobre liberdade de imprensa extraído em grande parte do regulamento espanhol. A própria noção de imprensa era reestruturada pelo governo interino do Reino, em Lisboa, que determinava: "do primeiro de janeiro do ano próximo de 1821 , por diante, a Impressão Régia se denomine = Imprensa Nacional = por ser esta uma propriedade da nação" (ANTT, Ministério do Reino, Livro 325: 39), ${ }^{1}$ fato que impulsionava a mudanças do título e concepção do jornal, que passaria a ser denominado Diário do Governo.

Se a maioria da sociedade portuguesa defendia de forma veemente um novo sistema de governo baseado na monarquia constitucional, havia também vozes dissonantes que criticavam a ideia de uma Constituição. Um folheto traduzido do espanhol que circulou por Lisboa, entre os idos de 1820 e 1821, fazia a seguinte reflexão:

Com que já temos constituição? Que escândalo! Que Horror! Que desaforo! Quem havia de pensar que ao fim de tantos anos que estão trabalhando os homens mais doutos mais respeitáveis para desterrar semelhante nome dentre nós, havia chegar um dia em que não só se ouvisse sem estremecer-nos, senão que se proclamasse, se exaltasse e ainda, para assim explicar-me se divinizasse? Em que tempo vivemos, Sr. d. Fernando, e que desgraça há sido a nossa ter alcançado este maldito século XIX. ${ }^{2}$

A verdade era que o raiar do século XIX trazia consigo um legado fundamental da Revolução Francesa: a discussão de temas políticos na arena pública pelos homens comuns. Isto é, se dessacralizava a política, tornando-a um tema a ser resolvido por toda a Nação. Nas palavras do historiador João Luís Lisboa, o início do século XIX marca a "altura dos grandes debates sobre as virtualidades da intervenção do homem na modificação e na condução

\footnotetext{
1 Documento direcionado à Joaquim Antonio Xavier A. da Costa, assinado por Manoel Fernandez Thomaz, importante dirigente do governo interino.

2 Lisboa. Punhal dos Corcundas. n. ${ }^{5}$, p. 41 . Lamentos políticos de um pobrezinho e preguiçoso que estava acostumado a manter-se à custa alheia, por O lamentador.
} 
da coisa pública" (Lisboa, 1991: 164), particularmente no contexto português, já que o Rei e sua Corte estavam a milhares de léguas de Lisboa, antigo centro do poder.

Sob essa nova perspectiva, a evolução e, posteriormente, a repercussão da Revolução do Porto nos dois lados do Atlântico impôs uma nova cultura política que se delinearia ao longo de 1821 e 1822, criando também o nascimento de um novo vocabulário político entre os homens ilustrados que pensavam os destinos do império. A "cultura política de uma sociedade compõe-se não só de conhecimentos e crenças que fundamentam as práticas possíveis no interior de um sistema político, como as normas estabelecidas para definir os direitos e deveres dos participantes como cidadãos", o que na prática, delimitava "as fronteiras das comunidades a que pertencem indivíduos e grupos, legitimando ou desqualificando as suas reivindicações", define a historiadora Lúcia Neves (2003: 25-26).

Se no início de 1821 a vigência das Cortes em Portugal já demarcava vieses importantes da monarquia constitucional a ser instituída no Império Português, no Brasil ainda se desenhavam as primeiras adesões às Cortes e à Constituição, cujo impacto e repercussão se deram de forma diferenciada em todo o Brasil, tão caracterizado pelas especificidades regionais. O Pará aderia ao projeto constitucional $\mathrm{em} 1^{\circ}$ de Janeiro de 1821, seguido do Maranhão e do Piauí. Em 10 de fevereiro, era a vez da Bahia e, em seguida, de Pernambuco. Nessas províncias, particularmente, o movimento constitucionalista foi "em grande parte resultado da ação de brasileiros libertos da revolução de 1817, cujos ânimos conseguiram ser totalmente sufocados pelos esforços dos respectivos governadores locais", afirma a historiadora Ana Rosa C. da Silva (2000: 292-293).

Apesar de as províncias do norte e nordeste terem concordado prontamente com o sistema constitucional, não houve uma perfeita sintonia nas tendências e motivações dessas províncias; pelo contrário, desde o início, a agitação pelo controle da situação se mostrava aguda. Todas essas capitanias, porém, convergiam em um ponto importante: faziam oposição ao despotismo do Rio de Janeiro, diferentemente das províncias do sul e sudeste, que assumiram um tom mais controlado.

Já no Rio de Janeiro, a particularidade dessas transformações aparecia desde 1820, quando a cena política brasileira já contava com o surgimento de novos protagonistas que, em 1821, seriam líderes de um importante movimento político em prol do juramento da constituição de Lisboa, ocorrido no largo do Rossio. Esse novo grupo era composto por proprietários de terras e comerciantes do Recôncavo da Guanabara e do Campo dos Goytacazes que se aliaram aos negociantes de gêneros de abastecimento e varejistas, além de bacharéis e militares, com o intuito de se contraporem aos interesses das 
famílias portuguesas e negociantes de grosso trato, ambos articuladores das esferas de decisão do Estado.

Denominado de liberais, seus principais representantes - Joaquim Gonçalves Ledo, Januário da Cunha Barbosa, José Clemente Pereira, Luis Pereira da Nóbrega de Souza Coutinho e Manoel dos Santos Portugal - eram homens que buscavam o enriquecimento e a ascensão na esfera pública, marcadamente por defenderem interesses antagônicos aos da alta burocracia portuguesa, representada pela nobreza emigrada, os comerciantes de grosso trato, como a família Carneiro Leão, e os ministros de Estado, entre eles Silvestre Pinheiro Ferreira e Vilanova Portugal.

26 DE FEVEREIRO DE 1821

O grupo dos liberais liderou uma das mais importantes manifestações políticas ocorridas no espaço público durante a governação de D. João VI. A parada militar ocorrida em 26 de fevereiro de 1821, no largo do Rossio na capital, exigia o juramento do Rei à Constituição de Lisboa e a substituição dos ministros de Estado e das pessoas que ocupavam os principais cargos políticos no governo. Eram favoráveis à volta de D. João VI para Portugal, sob a perspectiva de uma monarquia constitucional, com sede em Lisboa. Paralelamente a essas reivindicações, as atitudes do regente escancaravam a forte crise pela qual passava a monarquia portuguesa, cujo impasse era sinalizado para toda a sociedade fluminense inclusive com importantes contornos na imprensa.

Em 18 de fevereiro, D. João VI determinava a volta de D. Pedro a Portugal com o objetivo de "assegurar a felicidade da nação" e, assim, "restabelecer a tranquilidade geral daquele Reino; para ouvir as representações e queixas dos povos" (Gazeta Extraordinária do Rio de Janeiro, 1821, No 3). ${ }^{3}$ No dia 24, a Gazeta do Rio de Janeiro notificava em publicação extraordinária o decreto real que enviava o Príncipe Real ao Reino para consolidar a constituição portuguesa.

3 Na publicação do periódico a assinatura do Regente datava de 22 de fevereiro de 1821, folha 132 do Livro $8^{\circ}$. 
N.・ 3.

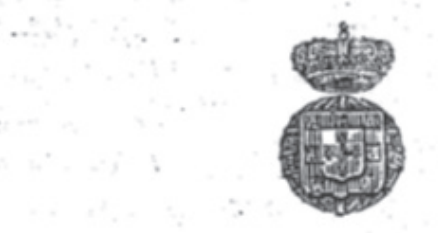

Anno 1821.

\section{GAZETA EXTRAORDINARIA \\ Do \\ RIO DE JA N EIRO.}

SABBADO \&4 DE FEVEREIRO.

Destrias. . vie genenct insitem :

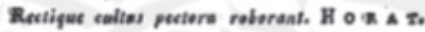

RIO DE' JANEIRO.

\section{E C R E T O.}

$\mathbf{E}$

Xigindo as circunstancias em que se acha a Monarchia justas e adequadas providencias pa. ra consolidar o Throno, e ansegurar a felicide. de da Naçio Partururza, Renolvi Dar a unaior prova do constante desvello, que $\mathrm{Me}$ anima pefo bem dos Meus Vassallos, Determinando que - Meu muito Amado e Prezado Filho, D, PE. pro, Principe Real do Reino Unido de Portu. gal, Braxil e Algarves, va a Portugal nunido da Authoridade e Instruç̧̋́es necessarias, para pôr logo em execuçín as medidas e providencias que Jolgo convenientes, a fim de restabelecer a tranquillidade geral.daquolle Reino; para ouvir as representaçốes e queixas dos $\mathrm{Po}$. vos; - para entabelecer as refórmas e melho. ramentos, e as Leis que possío consolidar a Constituiçio Portugerza ; e tendo sempre por base a justiça e o bem da Monarehia, procurar a eatabelidade e prosperidade do Reino Uni. do ; devendo ser-Me transidittida pelo Principe Real a mo-ma Constituiçio, a fim de receber, sendo por Min Approvada, a Minha Real San. ç̧ăo. Nio podendo porém a Conatíniçäo que em consequencia dos mencionados Poderes se - ha de estabelecer e sanccionar para os Reinos de Portegal e Algarver, ser igualmente adapta. vel e conveniente em todos os sens aniges e pontes essenciaes á Povoaşâo, luczlidade e mais circunstancias tifo penderotas ci mo attcndlitis deste Rrines de Bravil, assim cume as das llhas - Dominis.s Ulusmarines, que naso nerrcem menos a Muba Real Centenplacko e P.ternal Cuilates Hei por cunvenis nte Mandar censo. car a-rsia Certe es Precuraderts, que as Camaras des Cidales e Villas principacs, que tem Juizes Letrades, tanto do Reino do Brazil, cumo das Illas des Ageres, Madrira e Calo Verde ciegerem : E Sou outrosim Servido que eilas hajto de os escolher $e$ nomear see demo. $r a$, para que reenides aqui o mais prontamente que for pessivel em Junta de Cortes, com a Presidencia da Pessoa que Eu Hutier por bem escelher para este Lligar, nío sómente examinean e consultem o que dos referidos artigor for adaptavel ao Reino do Brozill, mas tambean $\mathrm{Me}$ proponhajo as mais reflreas, os melheramentos? os estabelecimentos, e quaes. quer outras providencias çue se entenderem es. senciaes ou uteis, on . ja para a seguian;a individual, e das prepriadade, boa administracko da Justica e da Fazenda, angmento do Commercto, da Agricultura, e Navegaço, Estudos e Educaçấo publica, en para outros quacrquer objectos conducentes a prosperidade e bew geral deste Reino, e dos Duaninics da Coroa Parfutoura.

$\mathbf{E}$ para secelerst aues traball.es, e prepa- 
rar as materias de qua deverís occupar-se: Sou tamban Servilo Crear desie já i hum. Comnis. sío co nontas de Pessas resilentes nesta Coirte. e por Mim nomsalas. qua entrarás logzo em exercicio, e continuaras con os Procurabres das Camiras qua se forein apresentanbo, a tratur de tolos os neferilos objectos, para cora ple. no coniscinsoto de caus $\mathrm{E}_{1}$ os Desilir. A Mesi ds D sensarz, do Paç, o tenha assim cotenfih. fagt pablicar e ex-catar, passan lo as Ortagi nacecrios is Cemuras, es mais Des juchn e participaçoss quat precias forems as quast tinban on fart, ass Governos das Pro. Qiacias pelas Secretariat da Estals. Palacio da $R$ ig do. 7atiry en dawiva de Fevereir, de mil

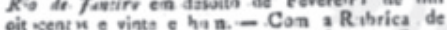
SUA MAG.3TT IOZ. - Enti confor as Pay'

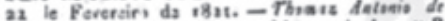

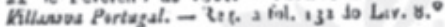

\section{E C R - E T O.}

Tenta Mialifac $\mathrm{C}$ ansas os Pracuratores

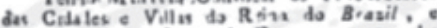
Ithas, pars en Jast de C urtes sa iratar des Dels Cinstiancioases. qua se discutem nas Car. tes da Libos, e dis milhoramzates que forera useis a Brazil. Cresals ha as Con nisslo de Pesias da Mra Crasalho part preparar estes

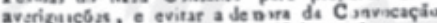

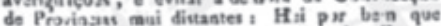
a provinas Comniriso stja compata das Petsoas gue constio da Ralach incluss, assiguth por Forerz Atanis de Villavous Portagal, Ministro e Secretario de Eitado dos Nutacin do Reino e a ella polerí assistir o M sa Procursdor da Curn, e ser chemalo qualquer dus ontros Five caes, oy E narezalor pislicus, qua far can. veaicate, $O$ masm? Minituro e Secretario de E. talo e ten's astim ententify, e tho participe, pata qas, se n depen lencia de o itr, Tiuals, ha. fó de entrar en exercicin. Palucio da Ris de Gaquin en vinte e tres de Ferereirs te nil aitoctatu e vint? e hos. - Co.s a Rabnea de SUA MAGESTADE.

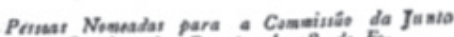
Creada pele Decrete de 18

Para Presidenie.

O-Marģuea de Aligrile.

Para Depulados.

O-Barlo de Santo Ausro.

$\mathrm{M}$ inienhor Alinelía.

Laiz Fout de Carvalho a Mrllo.

Antonio Lais Percira da Casba.

Atsonio Rolriguet Velloso de Olivira.

Job) Sevoriese Maciel da Coula.

Ciaills Miria Tondlet.

7oie te Soase de Mendonga Corte Rralo.

toid da Silva Lingas.

Muriaseo Jase Pereira da Fonsera.

Jilo Relinigues Perrira de Almeida.

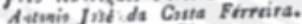

Francisco Xavier-Pires.

Joud Cutaro Gomet.

\section{Procurador da Corsa.}

Jue de Otiocira Botelho Pinto Mospacira.

$$
\text { Secritariot. }
$$

Masel Fucinto Nogurira da Gama.

Masod Girrira de Figweirrde.

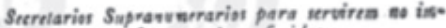
pedimate dos referides.

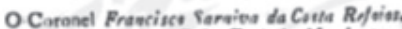
O Dusabargajor Jod, Jud de Mrwdonga.

Palacio do Rio de 7antirn en 23 de Feve. reim de 18 at. - Thomas Antanio de Villasavo Portiegal. 
O discurso real de D. João evidenciava os novos paradigmas que a sociedade como um todo estava compartilhando. Como soberano agora submetido a uma constituição feita e pensada pelo povo, D. João se via na posição de partilhar os poderes da nação, já que era por ela escolhido. A partir de então, o monarca devia obediência às leis que a sociedade legislava e promulgava nas Cortes, sendo reduzido seu espaço de negociação, que ficava sujeito a uma determinação coletiva vinculada aos trâmites do poder legislativo. A volta de D. Pedro para Portugal era uma forma de D. João VI conservar os laços reais nos dois lados do Atlântico para, em última instância, garantir a unidade e legitimidade do Império Português (Schiavinatto, 1999: 96-105). A circunstância era muito complexa, motivo pelo qual, no dia 23 de fevereiro, o Rei dava publicidade à relação dos membros da comissão da "Junta das Cortes" do Reino do Brasil. A ratificação dessa decisão ocorreria no dia seguinte, com a aprovação no Reino do Brasil da Constituição que estava sendo feita em Portugal. Os membros da comissão "eram os mesmos homens que no decorrer do governo joanino haviam acumulado enormes fortunas e se assenhorado da administração pública", afirma a historiadora Cecília Salles Oliveira (1999: 116). Na prática, a presença de personalidades como Tomás Antonio Vilanova Portugal, o Conde de Palmela e o Conde dos Arcos, perpetuava o mesmo poder político e as antigas condições de mercado vigente. Essa conjuntura conflitava diretamente com os interesses dos liberais fluminenses, que buscavam criar instrumentos jurídicos que legitimassem a sua preponderância sobre o mercado e a esfera pública. $\mathrm{O}$ foco da crise monárquica estava nas decisões reais que se passavam dentro do alto escalão governamental, fato que já se delineava pelo universo público de diferentes formas.

Desde a chegada da notícia da Revolução, o Rio presenciava um momento político de efervescência e ebulição. Já em meados de 1821, os habitantes da cidade produziam seus escritos que agora circulavam por todos os cantos em um clima de maior liberdade. Multiplicavam-se os manuscritos - cartas, anotações, papéis públicos - que geravam muitos burburinhos sobre o futuro do Império Português e, obviamente, contribuíam para o raiar de novas reflexões sobre a política real. Essa atividade ganhava tamanha dimensão que os próprios escravos passavam a esquadrinhar uma outra vertente de atuação, impostando suas vozes e opiniões, em uma clara perspectiva de sujeitos históricos agentes (Morel: 2005:232-233).

A manifestação de 26 de fevereiro de 1821 foi resultado dos dias de intenso conflito e tensão que ocorriam na órbita governamental. $\mathrm{O}$ movimento evidenciava o embate de posições políticas entre o governo e um grupo de cidadãos livres insatisfeitos, cujas relações comerciais eram muitas vezes perpassadas por elos de parentesco com os europeus e 
também pelo contato com a maçonaria, que os tornavam mais próximos dos revolucionários vintistas.

D. Pedro se responsabilizou pelas negociações entre os liberais - que exigiam a aprovação da constituição - e a palavra final de D. João VI, que aceitava o novo cenário político. Um contemporâneo dos fatos descreve que, desde o amanhecer do dia 26, quando todo o batalhão militar já se organizava na Praça do Rossio exigindo que o Rei se rendesse às Cortes, apareceu a figura de D. Pedro. Com um papel nas mãos, leu para as tropas que aguardavam a decisão real. "Tudo está feito: a Tropa pode ir a quartéis, e os oficiais vão beijar a mão do meu Augusto Pai" (Relação dos Acontecimentos do Rio de Janeiro no dia 26 de fevereiro de 1821 e algumas circunstâncias que o precederam e o produziram. BNP. Seção de Reservados, Cód. 10.759).

O bacharel Marcelino José Alves Macamboa argumentou que essa atitude não atendia as reivindicações e que o Rei deveria jurar as Cortes.

Em consequência desse momento de conflito, D. Pedro se comprometia em levar as solicitações dos revoltosos para D. João, inclusive com o pedido de afastamento de Paulo Fernandes Viana e Vila Nova Portugal, ambos homens de proeminência no governo. Depois da reunião com o monarca, que consentiu todas as exigências, D. Pedro voltou à praça e leu o decreto real de 24 de fevereiro. Foi ovacionado pela população que, sob vivas, aclamava o nascimento de um novo tempo. Alguns escritos da época exaltavam a relevância da atitude do príncipe, que foi considerado por muitos um herói.

Os Heróis sempre marcam

Um dia com grandes Feitos

Outros além levantaram

Padrões de valor inteiro;

Mas o Rio de Janeiro

Um herói em si achou

Que de mais glória coroou

26 de fevereiro.

(Poesia em aplauso dos heroicos feitos do memorável dia 26 de fevereiro 1821, Rio de Janeiro, Imprensa Régia, 1821).

Às onze horas da manhã, D. João estava in persona no Rossio para reafirmar as palavras e o pacto de lealdade do filho com o seu povo. Ao ser ovacionado, o Rei punha em prática os códigos de sociabilidade tão presentes e necessários nas relações hierárquicas e de subordinação vigentes na monarquia portuguesa: reverenciava o povo com beija-mãos, o que supostamente sinalizava para o restabelecimento da ordem. "D Pedro, ao ocupar a cena pública, sintetizava um modo de agir mais condizente com 
a intenção política liberal, que não reprime a revolta, o descontentamento, mas, ao contrário, sabe remanejá-los a seu favor", elucida a historiadora Iara Lis Schiavinatto (1999: 99). Com essa atitude, conseguia dissimular a derrota do rei, que cedia às exigências do povo.

Já no dia 28, o redator da Gazeta descrevia os fatos ocorridos dois dias antes pela ótica da conciliação entre os envolvidos. Segundo Guimarães, as múltiplas circunstâncias tiveram "vantajosos resultados" que podiam ser vistos através da "geral tranquilidade no meio dos acontecimentos quase sempre rubricados com sangue". No final da reportagem, o jornalista abria um diálogo com os leitores da folha, dizendo que bastava "transmitir uma singela e verdadeira exposição do que houve de mais notável neste dia singular a aqueles, que não tiveram a satisfação de o presenciar."

Era preciso que a Gazeta veiculasse essa versão dos fatos até porque a direção do jornal tinha ciência de que na cidade já circulavam outras informações sobre os acontecimentos advindos de além-mar, que vinham pelas correspondências particulares. Nessa mesma data, a Impressão Régia publicou um Suplemento à Gazeta $\mathrm{N}^{\circ}$ 17, que "complementava" as informações veiculadas na mesma edição. Ao contrário do que poderiam supor os contemporâneos, o jornalista não só defende explicitamente os interesses do povo, como também reverenciou o patriotismo dos revolucionários vintistas. Dizia ele: "Retumbou no Brasil a voz, que alçaram nossos Irmãos em Portugal, e o fogo do nobre patriotismo, acendendo-se nos peitos generosos dos habitantes do Rio de Janeiro, [que] rompeu as prisões que o detinham, e se manifestou com o maior entusiasmo". A participação popular era justificada "pelo desejo de ver melhorada a sua situação, ambicionando a glória de regenerar a Pátria." Ainda segundo o redator, como o povo não podia realizar tal empreitada por si só e "ultimar tão grande obra, convidou a cooperação daqueles que, por mais de uma vez tem salvado, e achou no brio, valor e honra dos mesmos, o auxilio, de que precisava", em referência aos militares, a Tropa e ao grupo dos liberais.

Nessa publicação há um rompimento com o discurso real que glorificava o monarca e sua infinita benevolência para com o seu povo. O gazeteiro assume, inclusive, a existência de condições sociais conflituosas (sobretudo para os menos privilegiados) dentro do sistema absolutista português. Diante de tamanha ousadia, já que tudo isso tinha sido dito em um jornal oficial, é bem razoável que os diretores do periódico estivessem inquietos com as consequências adversas do processo político desde a Revolução do Porto e, por isso mesmo, buscassem uma rearticulação do discurso da folha. 
O ano de 1821 foi, decisivamente, um período de grandes e importantes mudanças na vida sociopolítica e cultural do Brasil. As múltiplas manifestações de ordem pública só cresceriam ao longo do ano, sobretudo depois do movimento constitucionalista de fevereiro. Nesse cenário, os cafés e as livrarias se tornavam locais privilegiados das discussões políticas, apesar de o absolutismo não ser ainda uma página virada da história luso-brasileira. "Diante do poder Absolutista, havia um público letrado que, fazendo uso público da Razão, construía leis morais, abstratas e gerais, que se tornavam uma fonte de crítica do poder e de consolidação de uma nova legitimidade política", afirma o historiador Marco Morel (2005: 201).

O mês de março marcaria importantes contornos nessas transformações que, em âmbito mais amplo, estavam imersas nas novas problemáticas vigentes no Império luso-brasileiro. Nesse mês, surgiam três jornais no Rio - uma absoluta novidade -, já que até então todo papel impresso que circulasse pela cidade (incluindo-se aí a imprensa) era de domínio privado do governo, através da Impressão Régia e, portanto, necessitava de uma licença real para circular.

O amigo do Rei e da Nação, de Ovídio Saraiva de Carvalho e Silva, foi um periódico que circulou entre os meses de março e junho de 1821 . O texto era escrito em forma de artigo, sendo publicado em três partes. Para além deste, nascia também $O$ Bem da Ordem e O Conciliador do Reino Unido. Enquanto o primeiro tinha como redator o cônego Francisco Vieira Goulart, o segundo foi dirigido por José da Silva Lisboa, o visconde de Cairu, todos eles homens ilustrados pertencentes a um estrito círculo cultural diretamente ligado à realeza. Diferentemente de $O$ amigo do Rei e da Nação, O Bem da Ordem foi uma coleção de dez edições, escrita em formato editorial, que circulou até o mês de dezembro de 1821. Em todos os números, o redator primava pela continuidade temática do que havia sido discutido nos exemplares anteriores. Já O Conciliador do Reino Unido teve apenas sete números, circulando entre $1^{\circ}$ de março e 28 de abril de 1821 .

Todas essas novas folhas, juntamente com a Gazeta do Rio de Janeiro, debateriam questões políticas essenciais da época: as Cortes, a constituição, a ideia de opinião pública e a liberdade de imprensa; esta última uma exigência dos revoltosos vintistas aceita por D. João VI no "memorável" dia 26 de fevereiro de 1821. Debater as vantagens e prejuízos da liberdade de imprensa era uma questão central da época, afinal de contas se constituía como um dos principais pilares do liberalismo político, então nascente no mundo luso-brasileiro. Cairu, que era diretor da Gazeta do Rio de Janeiro desde 1808 
e também censor régio, dedicou três números de seu jornal $O$ Conciliador do Reino Unido para pensar sobre essa problemática.

Nessas edições, criticava as ideias de um folheto anônimo impresso no Brasil que se popularizara na sociedade carioca justamente por defender a absoluta liberdade de imprensa. ${ }^{4} \mathrm{O}$ comentário do censor sobre tais reflexões é um excelente termômetro das mutações que permeavam o universo público da Corte. A "liberdade de imprensa é hoje reclamada sem limites, como direito do homem e do cidadão pela mania do século, e fantasia de sofistas, que confundem a saudável reforma com a horrorosa mudança na constituição do Estado", defendia. Com esse discurso, Cairu temia que a imprensa se convertesse em uma "maquina infernal, para explosões revolucionárias", pois, segundo ele, certamente estaria nas mãos dos pregoeiros de desordens, que, dizendo ter chegado à idade da razão, usá-la-iam para propagar erros terríveis em escritos incendiários. Em outras palavras, o nobre desejava criar limites para a liberdade de expressão. Ovídio Saraiva de Carvalho e Silva, bacharel formado em direito pela Universidade de Coimbra, também ajuizava sobre o futuro da imprensa no Brasil, principalmente depois do decreto de 2 de março de 1821 que suspendia a censura prévia. Segundo ele, todas as conversas miúdas que invadiam os diferentes lugares de sociabilidade da Corte tinham como tema a esperança das pessoas em relação aos melhoramentos decorrentes das novas possibilidades da livre escrita (O Amigo do Rei e da Nação, n. 1, s.d: 5).

Apesar de tamanha agitação social, Carvalho e Silva interpretava o decreto de 2 de março mais como uma benesse do soberano do que como uma conquista de toda a sociedade. Por essa ótica, classificava os escritores em dois grupos bem distintos entre si: o cidadão benemérito e o criminoso. “(...) os mesmos tipos, que apontarem as virtudes, hão também [de] assinalar os delitos", defendia o fiel vassalo de D. João (O Amigo do Rei e da Nação, n. 1, s.d: 7). Na prática, porém, o Rio já vivia sob a diversidade de olhares, o que constituía um passo fundamental nas discussões sobre temas de interesse coletivo.

Apenas o Brasil o sabe, não mais se esconde o entusiasmo de seus habitantes, e sem que o medo o estorve, o sentimento avulta, a opinião se fortifica, e qual seja a vontade universal não entra em dúvida. O Bem, que a todos resultava na mudança era muito claro, muito simples para que às vistas mais grosseiras pudessem ficar oculto. A Bahia soltou o primeiro grito de Constitucional e, e seu eco, retinindo no Rio de Janeiro, encontrou a resposta em um grito semelhante.

4 Ver edições de n. ${ }^{\circ}$ S 5,6 e 7 
Apesar do partido imediato, que se nutria da miséria da Nação, e iludindo o Monarca, tentava escurecer a seus Olhos os raios da verdade; apesar dos Gênios mal fazejos, aos quais não convinha a menor variação na marcha do Governo: alguns daqueles Portugueses, a quem nada atemoriza, logo que se trata da salvação da Pátria, e alguns honrados e dignos Militares, tomam a si a Grande empresa, prestão-lhe energia, e conseguem finalmente na manhã do dia $26 \mathrm{de}$ Fevereiro realizar os seu ardentes votos com Aprovação do Benéfico Soberano

Às vistas de todos estão fixas na Administração da Causa Pública, e vêm satisfeitos, que os novos Ministros, e novas Autoridades vão confirmando a boa opinião da sua escolha, tanto mais grande ( $\mathrm{sic}$ ) quanto mais difícil na crise, em que foi feita, e da qual não devia retardar-se.

O público por justos motivos queixoso, e talvez indignado: agora que a verdade já não é crime, agora que a verdade já pode intrépida avesinhar-se ao trono o Soberano conhecerá cada vez mais, que a linguagem muito raras vezes tocou nos seus ouvidos. Não digo, que em todas as Autoridades existisse a corrupção; uma tal linguagem seria um crime seria manchar os Portugueses, e supor entre eles mais perversos, do que honrados. É certo, porém, que de grandes, e mesmo de pequenas Repartições, brotavam ordens, e emanavam planos que se o nosso Bom Rei os conhecesse, não ficariam impunes seus autores.

\section{(...)}

As nossas ideias mais livres agora, apuradas por sábias combinações, e por um sisudo critério, servirão de aperfeiçoar os costumes: as Ciências, e as Artes serão melhoradas entre nós, banida a estupidez, e o mérito exaltado. O fogo dos Gênios iluminados não será mais sufocado, e sem que transponham as balizas, que a Decência e a Razão lhes assinala, sem que fatais parcialidades os desvairem, veremos defender o justo, proscrever o injusto, e melhorando o que for bom, tornar feliz a Sociedade, enriquecê-la de bons Escritos, não só pelas Pátrias produções, mais ainda pelas traduções e ampliações daquelas com que as outras se enobrecem.

(O Amigo do Rei e da Nação, n.1, s.d.:3-7). 
N. 19.
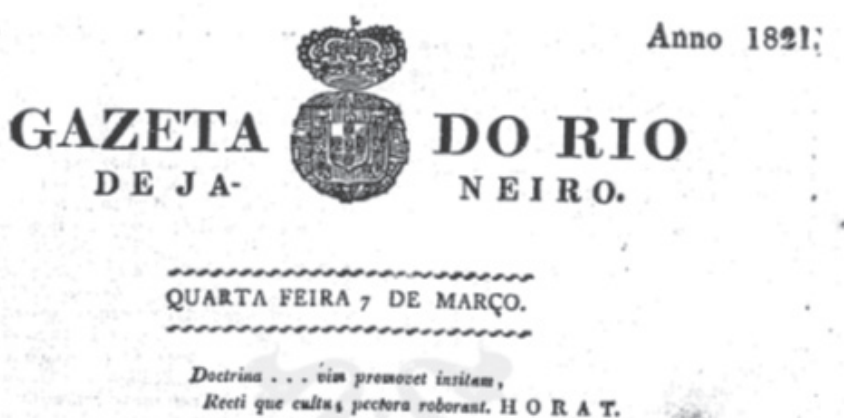

\section{RIO DE JANEIRO.}

$\mathbf{T}$ Erça feira, 6 do corrente, pelas 3. horas da tarde, us fogos de artificio, as salvas das Fortalezas e da Esq uadra, e os repiques dos si. nos advertiráo os Portugurzes de que - Ceo thes havia concedido mais hum beneficio, na feliz seccessio dos Seas Augantos Menarcas; Sua Alteza Real a Princeza Real do Reino Uni. do de Portugal, e do Bratil e Algaroes ha. vendo dado á laz buin Principe, Herdeiro das Virtudes de Seus Augustus Pais e Avós. Os nossos coraçbes, que ainda trasbordio de ju. bilo pelo fatstissimo donativo, cum que o Se. nhor D. JOXO VI., Nasso Águsto Suberano, bavia fixado a noss felicilade, toráo sobresal. sados de bum novo alvoroça, $e$ a visivel proteçáo do Altissiaso sobre Portugal exigio as nossas aç̧бes de graças. Apresiando-nos a tomar parte no publico regozijo, reiervamos por falta de tempo para- o N." seguiate a narraçio das devidas demonatrapües do apreço, que merece tão appetecido successo.

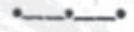

O singular Beneficio, que o Senhor D. JOXO VI., nosso Amabilissimo Soberano, concedeu aos seus ditosos Vasuallos pelo sempre memoravel Decreto de 24 de Fevereiro, ao mesmo tempo, que he o sagrado Palladio da nossa liberdade, he o matancial perenne da nosua fe. licidade. Exceeleria sem duvida as nossas aca. ahadas forças memorat todos os bens, que se derivão daquella fonte inexhaurivel. Limitando. nos porf́m a consideraçbes parciaes, temos neate momento de unencionar o Decreto de 2 de Mar. so corrente, como hutna époea notavel na his. toria Portagueza.

A liberdade da Imprensa era sem duvida huma consequencia dos principios liberaes, que havido indurido a SUA MAGESTADE a ado. ptar huma nova ordem de cousas ; mas, segundo o sentimento do celebre Montrioutea, as for. malidades da justiça sio necessarias á liberdada. SUA MAGESTADE se deliberou portanto a uncionar aquella franqueza, de que se tem derivado tantos progressos i propagaçio das lu. zes, e ́a communicaçío das noticias, Mas co* mo (segundo a opiniåo do mesmo grande Eutadista) - espirite de moderaça deve ier o do le gislador; 0 ben politice, como obem moral, se acba sempre entre dis lisiles, a sabedoria do Governo soube cohibir os excessos, que ta graves e profundas feridas tem feito na Religifio Christá, tio affastada do puro despotiamo, na opinilo do citado Autor, na moral pura do Evangelho, respeitada ainda por hum dos maio. res campióes da incredulidade, e nos principios da verdadeira politica, e da segurança pessoal, que he o mais saboroso fructo da Sociedade. Todas estas grandes vistas politicas se achio no seguinte Decreto, que offerecemos $\mathbf{a}$ attençio dos Leitores.

$$
\text { D E C R E T O. }
$$

Fazendo-se dignas de Minha Real Conside: naçlo as reiteradas Representaçbes, que Petsoas doutas e zelosas do progretso da Civilisaçio e das Letras tem feito subis a Minha Soberans 
Cinco dias depois, em 7 de março, o decreto era publicado na Gazeta do Rio de Janeiro. O comentário do redator não só admitia que a liberdade de imprensa fosse uma consequência dos princípios liberais, como também a referenciava como fator que propugnava o progresso e as luzes.

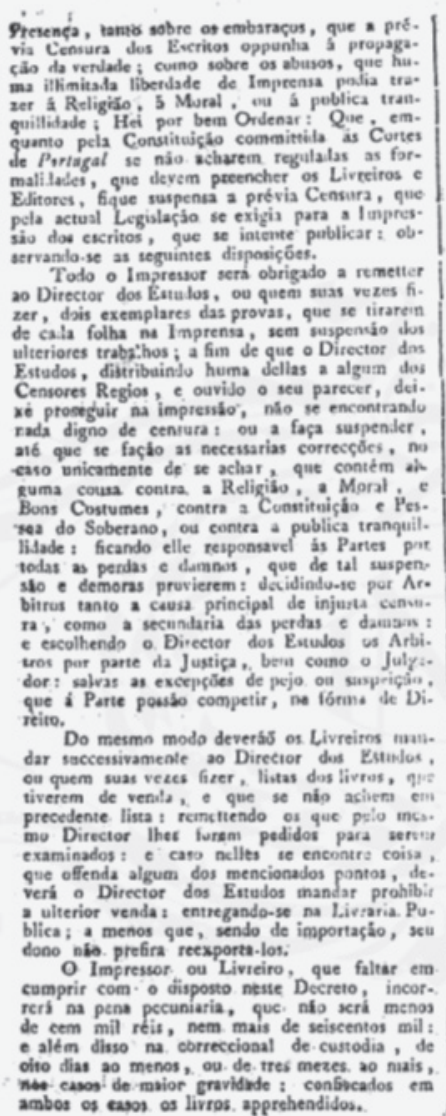

E come pelo Acto erpontaneo da Mi nh Scberania, com que Hei pur bem suspeniler at a promulgaço da Constituiça a Censura prévia. que prende e retarda a pablicaçho e cir. culaça dos Exritos, náo he, nein polis ser Minha Intença abrir a porta a libertia disoluçáo no abuso da lemprensa : Hei por espressamene declarabs, que se por alguin modo se imculuzitern nu Publico, apecar Jas cantslas. acim ondenadas, ou pela falta da sua observancia, Escritus scdiciusos, ou mbrersivos da Reliģifo e da Moral ; Gquean responsaveis is Justicas deates Meus Reinus , pela natureza e cunsequencias das dontrinas ou asserçő́es nelies conilis, em primeire lagar scus Autares: a guando estes nho sejso conhecidos, os Editores: a a final us Venjedores ou Dietribuilares, no caso que se lines prove conhecianento o cumpli. cilade na disserninaço de taes dumtrinas, ou asserç⿰⿸尸巳

A Meza do Desembargo do Paço o tenha assim enteadido, e faça executar. Palacio do Rio de Jaserire aos, de Março de 18a1. - Cora Rubrica de SUA MAGESTADE.

En consequencia do que havemos dito nos $\mathrm{N}$, ot precedentes das espontaneas e repetilas demonstraciéss de prazer, que o publico á porfí tem dado, temos a satiofaçás de accrescentur que a iltuminaçio $\mathrm{tcm}$ cuntinualo todas as neiiss, e que em tedas clias tem criado o Real Theatro de 8 . Jnd, illuminado . e se tem repetislo cum o mesmo cothusianso os Vivas i Reliziso, a SUA MAGESTADE, a S. A. R. o PIIINCIPE REAL, e i Canstituiçio em Presenca das Effigies de \$S. MM. e AA. RR. cantando-se us hymnos, e recitando-se vernos al. lovives, ta mesima maneira, que unencionimos nas Gazetas precedentes.

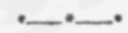

Temos muito prazer em elogiar as acerta. das medilas, com que a Pulicia tem vigiado subre a icgeranęa publica, das quacs se tará huma completa ides, lendo" a scguinte Edital.

Antonio Lurz Iratira da Cusha, do Conselbo de SUA MAGESTADE, ido da Sua Real Faresda Fidalgo da Caza Reat, Comimendadur da Orden de CArisu, Deperade da Real Jumta do Conenerrio, Ficral das Mercis, - Iniendente Giral da Policio desta Corie a Rrimo de Brasi, Es. Es. U6.

Fạo azber as que o presente Edital víg

O decreto de 2 de março transferia a censura dos manuscritos para as provas tipográficas. Isto é, na prática, mudava-se o tipo de "censura" praticada pela Coroa: regulavam-se os direitos dos editores e impressores, ao mesmo tempo em que estes ficavam restringidos à vigilância dos homens ilustrados da órbita real responsáveis pela "boa" condução das discussões. Apesar dessas controvérsias, a partir de então o Rio de Janeiro abria as portas para o florescimento da imprensa que pautaria os primeiros debates políticos na 
arena urbana. Nesse mesmo dia 7 de março, D. João notificava a decisão de voltar para Lisboa deixando aqui D. Pedro, seu legítimo sucessor que ocuparia na sua ausência o centro do poder no Brasil. Para evitar maiores conflitos políticos, que na vida cotidiana já se mostravam cada vez mais acirrados, o Rei também convocava para abril a reunião de eleitores paroquiais para a escolha de seus representantes nas comarcas, responsáveis por elegerem os deputados que comporiam as Cortes, em Lisboa.

Uma semana depois, no dia 14 de março, era estampado na primeira página da Gazeta o decreto real. A decisão da partida foi compreendida como uma prerrogativa indispensável para a manutenção do Pacto Social. Por essa razão, D. João aceitava e jurava por "toda a Nação o dever do soberano de assentar a sua residência no Lugar, onde se ajuntarem as Cortes, para lhes serem prontamente apresentadas as Leis, que se forem discutindo, e deles receberem sem delongas a Sua indispensável Sanção." Compreendia sua partida como "um dos mais custosos sacrifícios, de que é capaz o meu Paternal e Régio Coração", estendendo o momento da sua tristeza para rememorar a trajetória histórica da monarquia portuguesa, particularmente quando ele próprio fora personagem principal. Ressaltava a separação - pela segunda vez - de seus vassalos, "cuja memória me fará sempre saudosa e cuja prosperidade jamais cessará de ser em qualquer parte um dos mais assíduos cuidados do meu Paternal Governo”.

Abril foi um mês de muita tensão no Rio. As tropas de linha aguardavam com ansiedade a reunião marcada para o dia 22, que definiria os personagens ou eleitores das comarcas para a representação do Rio de Janeiro nas Cortes Gerais. Estes ameaçavam novas manifestações e, com o apoio do povo, mantinham a cidade em constante agitação, ao ponto de Silvestre Pinheiro Ferreira sugerir ao Rei que entregasse aos autores da "desordem" a sustentação da tranquilidade pública (Ferreira, 1877: 182-183). José Domingues de Attaíde Moncorco, um memorialista do período, considerava horrível o quadro da Corte nessa época. "Tal a apaga que esta cidade leal e hospitaleira recebeu daqueles a quem acolheu, elevou e nutriu por tantos anos. Ela via-se onerada de impostos mal aplicados e novos no país, sem marinha, sem comércio e sem numerário", bradava o contemporâneo. Além disso, ainda exaltava sua revolta com "uma Corte que ostentava luxo asiático; e como se ainda estes males não fossem sobejos, o Rio de Janeiro via germinar no seu seio mil partidos diversos e destrutores." Segundo ele, tais fatores foram responsáveis pela partida precipitada do Rei (Moncorvo, 1864: 274). Paralelamente, ocorria a formação das Juntas de Governos Provinciais. Pará, Pernambuco e Bahia mantinham uma posição revolucionária: os líderes expulsaram os capitãesgenerais do poder e instituíram a eleição imediata de representantes da terra. Já São Paulo e Minas Gerais compuseram o poder e a representação pela 
aliança dos antigos governadores, que simbolizavam a força do governo absolutista. Apesar das diferenças, essas transformações na recomposição dos poderes regionais significavam, nas palavras da historiadora Maria de Lourdes Viana Lyra, "a incorporação definitiva e de direito, dos nascidos no Brasil nas funções administrativas da Monarquia" que, na prática, abria o caminho para a flexibilização do sistema (1994: 196).

Diante desse cenário, D. João resolveu antecipar em um dia a reunião, que ocorreria, então, no dia 21. Entre os dias 19 e 20 eram afixados nos principais pontos da cidade os editais que determinavam a mudança da data. A antecipação do encontro foi uma estratégia muito bem planejada pelos nobres emigrados e comerciantes de grosso trato para que mantivessem o controle das decisões e impedissem ou minimizassem a presença e os votos do grupo liberal. "A leitura deste edital causou sensação prodigiosa, instruiu o povo da sua força e animou os mais tímidos. Lavrou por toda a cidade a notícia de que a junta eleitoral ia deliberar sobre um novo governo e que El-rei queria que o Brasil fixasse regido por pessoas da sua confiança", relembrava Moncorvo em maio do mesmo ano (Moncorvo, 1864: 276).

Os liberais, todavia, não acataram a alteração. Com o apoio do povo, das tropas milicianas e regimentos policiais organizaram uma manifestação na Praça do Comércio cujo intuito era fazer pressão ao governo e tentar viabilizar as diretrizes e os representantes que atendessem aos seus interesses. No dia 22, o povo - na maioria à margem do processo eleitoral -, compôs a multidão na praça. O sentido de povo no Brasil no alvorecer do Oitocentos estava estritamente associado aos critérios de representatividade, isto é, pelas regras da época vigente no quadro do liberalismo constitucional, eram as eleições censitárias e indiretas que designavam quem seriam os parlamentares. Apesar disso, o Rio ainda mantinha uma concepção tradicional do esquadrinhamento do espaço público (uma vez que as praças existiam, sobretudo devido à sociabilidade da Coroa, da nobreza, dos militares e da Igreja). Como nos elucida o pesquisador Marco Morel, essa situação já começava a mudar devido às ocorrências e "tentativas de apropriação de outros espaços, que assim se tornavam híbridos", pois marcava a presença de diferentes camadas da população na cena pública, $o$ que, na prática, contribuía decisivamente para o "movimento de passagem para a condição de súditos-cidadãos" (Morel, 2005: 165).

Ao contrário do que imaginavam os liberais, a população livre das mais diversas camadas sociais também intervinha nas propostas políticas exigindo que suas vozes e interesses fossem contemplados. Depois de lido o edital, o povo se convenceu de que tinha o direito de fazer os comentários e reflexões que melhor lhes conviessem, por isso pediram em uma voz uníssona "Queremos a constituição espanhola interinamente!" (Moncorvo, 
1864: 277), que vigorava desde 1812 e cujo texto exercia grande influência no desenvolvimento do constitucionalismo espanhol, português e também norte-americano.

Esse posicionamento mostrava um viés fundamental da atuação do "povo" tão subestimado pelas elites luso-brasileiras: havia uma insubordinação às decisões e aos projetos políticos defendidos pela elite proprietária de terras, o que representava um perigo para os grupos em conflito, fossem eles a alta nobreza portuguesa e os ricos negociantes fluminenses, ou mesmo o grupo dos ditos liberais.

Em meio ao rebuliço, os membros do partido realista ou os homens próximos à $\mathrm{D}$. João pediam tranquilidade e admitiam o juramento à constituição espanhola. "Os clamores aumentando em todo o salão, muitos membros da junta tomaram a palavra para os sossegar (sic), e os eleitores mais adictos às novas opiniões, depois de terem apreciado em silêncio o espírito do seu corpo, vendo que o partido realista estava comprimido por um terror pânico julgaram chegada a ocasião de se aproveitarem do ardor popular: eles em alta voz pediam ao povo que se tranquilizasse, prometendo-lhes que se havia de julgar a constituição que pediam, e afiançando o presidente para que estava munido de poderes reais para os atender", narra Moncorvo, uma figura ocular dos fatos.

A violência e o acirramento das diferentes posições políticas alteraram os rumos da reunião. No auge das discórdias, D. Pedro autorizou a atuação repressiva das tropas de linha e de regimento da divisão portuguesa que colocavam um ponto final à manifestação. $\mathrm{O}$ saldo de tamanha violência, no entanto, era um alto número de mortos e feridos. “(...) pessoas do povo foram indiscriminadamente mortas, e um número maior, lançando-se ao mar com precipitação, encontrou nas ondas a morte que evitava. Porém, $\mathrm{o}$ que mais denegria estes soldados desencaminhados e ferozes foi que, não contentes de tirarem a vida a seus próprios concidadãos, traficavam nelas, recebiam ou roubavam o que achavam de mais precioso, e saquearam os móveis de prata do serviço da casa", descrevia o mesmo memorialista (Moncorvo, 1864: 288).

A grande repercussão do episódio teve diferentes versões pela cidade. Cada um a sua maneira recontava o fato ressaltando os detalhes que mais lhe interessavam. Diante de tamanha afronta ao poder real, era necessário que o gazeteiro da monarquia publicasse uma reportagem sobre o ocorrido, em 25 de abril. Depois de descrever a razão do evento ocorrido na Praça do Comércio - a eleição dos nomes dos compromissários para atuação nas Cortes -, Araújo Guimarães falava em nome da monarquia, comentando a enorme decepção que o povo havia causado diante dos olhos do Rei e seus representantes. "Confessamos ingenuamente que nos entregávamos 
de antemão a sentimentos de júbilo por uma acizada (sic) eleição, e nos felicitávamos do desempenho de tão grato dever. Mas quanto são errados (sic) os juízos dos homens!" Afirmava ainda que, por ter as esperanças malogradas, a dor era pungente. Ressaltava, contudo, que "devemos ser fiéis expositores de acontecimentos desastrados, que tiveram origem na inconsideração, progresso na exaltação de sentimentos ilegais, e fim em desgraças, que a maior vigilância não pudera antever."

A circunstância pela ótica das autoridades reais era desastrosa e a fala do redator deixava claro que a razão dessa catástrofe tinha uma explícita relação com a atuação do povo - considerado por Guimarães "inimigos da causa pública" -, justamente porque reivindicava a sua participação política. Segundo o jornalista, os revoltosos "sofregamente procuravam medidas violentas, e providências arrebatadas. Discursos sediciosos, vozes tumultuosas substituíram a tranquilidade e sangue frio necessários em deliberações de tanta importância" que acabaram por abrir espaço para objetivos "alheios àquela assembléia e, portanto nulos". Para os representantes da monarquia, esses personagens acabaram por produzir muitos rumores anárquicos ao invés de consagrar o importante voo em direção à liberdade, o que causava profundo pesar aos cidadãos que têm verdadeiro amor pela Pátria.

A reflexão publicada na folha oficial três dias depois do episódio revelava muito da visão que os detentores do poder possuíam dos agentes sociais populares que estavam inseridos na transformação política de tamanha envergadura para os destinos do Império luso-brasileiro. Compunham uma multidão ainda sem coesão coletiva em prol dos ideais que defendiam, mas que já possuíam a consciência do seu potencial de transformação ou, ao menos, já começavam a compreender a força inerente ao poder de suas palavras quando expunham as contradições e problemas da realeza no espaço público.

Em 26 de abril, quatro dias após esse episódio lamentável, D. João VI partia para Portugal. D. João, a Rainha D. Carlota e o príncipe D. Miguel eram acompanhados por mais ou menos quatro mil pessoas que compunham a comitiva real. Por ironia do destino, o regresso da corte joanina foi feito à francesa, às pressas, mas sem alarde. D. João VI voltava para o Reino muito menos Rei do que quando chegara ao Brasil, ainda Príncipe Regente. Acuado politicamente, o silêncio da partida demonstrava o medo do monarca diante das possíveis manifestações populares que já faziam parte do cotidiano de seus súditos-cidadãos em ambas as margens do imperial Atlântico português.

Dois dias depois da partida, a edição 34 da Gazeta do Rio de Janeiro estampava a notícia que já era de conhecimento de todos na cidade. $\mathrm{O}$ jornalista exaltava as provas de amor do soberano aos seus vassalos e todo o seu empenho em prosperar o Novo Mundo. O embarque da realeza 
pela nau D. João VI era descrito da seguinte forma: "Um excelente dia, um vento do NE, fresco e aturado fizeram sobressair esta cena brilhante, e ao mesmo tempo dolorosa”. Nessa mesma edição, a Gazeta publicava o primeiro artigo de D. Pedro na imprensa. Intitulado Habitantes do Brasil, o regente comunicava seus súditos acerca dos objetivos gerais de sua real administração. Em 28 de abril de 1821, portanto, sob as rédeas do Príncipe Regente, que ficara para dar unidade ao Império, começava uma importante fase da história do Brasil. O período joanino ficara para trás. 